\title{
Governança universitária e rankings acadêmicos à luz da literatura acadêmica brasileira'
}

\author{
University governance and academic rankings in the light of Brazilian \\ academic literature
}

\section{Gobernanza universitaria y rankings académicos a la luz de la literatura académica brasileña}

\author{
Marco Wandercil ${ }^{2}$ \\ Faculdade Santa Lúcia de Mogi Mirim, Faculdade Casa Branca de Casa Branca, Professor. \\ https://orcid.org/0000-0002-9295-1051 \\ Adolfo-Ignacio Calderón ${ }^{3}$ \\ Pontifícia Universidade Católica de Campinas, Programa de Pós-Graduação em Educação, \\ Bolsista de Produtividade Científica do CNPq, Professor Titular. \\ https://orcid.org/0000-0001-6534-2819 \\ Francisco Anibal Ganga-Contreras ${ }^{4}$ \\ Universidad de Tarapacá, Chile, Departamento de Educación de la Facultad de Educación y \\ Humanidades, Professor Titular. \\ https://orcid.org/0000-0001-9325-6459
}

Resumo: Partindo do pressuposto que a temática da governança universitária e sua interface com os rankings acadêmicos é pouco explorada em termos de pesquisas científicas no âmbito acadêmico brasileiro, o presente estudo tem como objetivo traçar e analisar o estado da questão na literatura acadêmica brasileira sobre a governança universitária e sua inter-relação com os rankings acadêmicos com o intuito de identificar as tendências predominantes, tendo como indicadores analíticos: conceito, metodologia e bases epistemológicas. Realizou-se análise bibliográfica de estudos produzidos sobre a temática, tendo como corpus analítico a produção científica brasileira sobre governança universitária

\footnotetext{
Este artigo é uma versão modificada e ampliada do trabalho publicado em livro organizado por Fossatti e Jung (2019) sobre governança educacional em ibero-américa. É um dos produtos, versão completa, do projeto "Governança universitária em tempos de rankings acadêmicos, índices e tabelas classificatórias (Rankintacs) nas instituições de educação superior brasileiras" (Processo $n^{\circ}$ 311.333/2017-6), financiado pelo Conselho Nacional de Desenvolvimento Científico e Tecnológico (CNPq) do Ministério da Ciência, Tecnologia, Inovações e Comunicações do Brasil, coordenado pelo Dr. Adolfo lgnacio Calderón, Bolsista Produtividade do CNPq.

2 Doutor e Mestre em Educação pela Pontifícia Universidade Católica de Campinas.

3 Pós-doutor em Ciências da Educação pela Universidade de Coimbra, Portugal; Doutor em Ciências Sociais pela Pontificia Universidade Católica de São Paulo.

4 Pós-doutor em Ciências Humanas pela Universidad del Zulia, Venezuela; Doutor em Gestão Estratégica pela Universidade de Sevilla, Espanha.
} 
e sobre rankings acadêmicos em termos de artigos científicos, dissertações de mestrado e teses de doutorado. Entre os principais achados desta pesquisa: 1) identificou-se a incipiência da temática governança universitária na literatura acadêmica brasileira, sendo a maioria das produções nas ciências humanas; 2) verificou-se tratar de um tema altamente polissêmico que converge para o processo de tomada de decisão, envolvendo múltiplos aspectos da vida universitária como, gestão do conhecimento, gestão financeira, autoavaliação, influência política, transparência, participação e envolvimento dos stakeholders, 3) inferiu-se que o conceito de governança universitária está alinhado a uma estrutura ágil e flexível no processo de tomada de decisão, frente a um cenário de grandes mudanças e múltiplas demandas, ultrapassando aos conceitos básicos de gestão universitária; 4) identificouse explicita inter-relação da governança universitária com os rankings acadêmicos, sendo estes, considerados ferramentas importantes de governança, quando considerados pelas universidades em seu planejamento estratégico para superar fragilidades identificadas.

Palavras-chave: Governança universitária. Rankings acadêmicos. Educação Superior.

Abstract: Assuming that the theme of university governance and its interface with academic rankings is little explored in terms of scientific research in the Brazilian academic context, this study aims to trace and analyze the state of the issue in the Brazilian academic literature on university governance. and their interrelationship with academic rankings in order to identify the predominant trends, having as analytical indicators: concept, methodology and epistemological basis. Bibliographic analysis of studies on the subject were performed, having as analytical corpus the Brazilian scientific production on university governance and academic rankings in terms of scientific articles, master's dissertations and doctoral theses. Among the main findings of this research: 1) we identified the incipience of the theme university governance in the Brazilian academic literature, being most of the productions in human sciences;2) it was found to be a highly polysemic theme that converges to the decision-making process, involving multiple aspects of university life such as knowledge management, financial management, self-assessment, political influence, transparency, participation and stakeholder involvement; 3) it was inferred that the concept of university governance is aligned with an agile and flexible structure in the decision making process, facing a scenario of great changes and multiple demands, surpassing the basic concepts of university management; 4) an explicit interrelationship between university governance and academic rankings was identified, which are considered important governance tools when considered by universities in their strategic planning to overcome identified weaknesses.

Keywords: University governance. Academic rankings. Higher Education.

Resumen: Partiendo del presupuesto de que el tema de la gobernanza universitaria y su interfaz con los rankings académicos es poco explorado en términos de investigación científica en el contexto académico brasileño, el presente estudio tiene como objetivo rastrear y analizar el estado de la cuestión en la literatura académica brasileña sobre gobernanza universitaria. y su interrelación con los rankings académicos para identificar las tendencias predominantes, teniendo como indicadores analíticos: concepto, metodología y bases epistemológicas. Se realizó un análisis bibliográfico de estudios producidos sobre 
el tema, teniendo como corpus analítico la producción científica brasileña sobre gobernanza universitaria y sobre rankings académicos en términos de artículos científicos, disertaciones de maestría y tesis doctorales. Entre los principales hallazgos de esta investigación: 1) se identificó la incipiencia del tema de la gobernanza universitaria en la literatura académica brasileña, siendo la mayoría de las producciones en el área de humanidades; 2) se encontró como un tema altamente polisémico que converge con el proceso de toma de decisiones, involucrando múltiples aspectos de la vida universitaria como, gestión del conocimiento, gestión financiera, autoevaluación, influencia política, transparencia, participación e involucramiento de los grupos de interés; 3) se infirió que el concepto de gobernanza universitaria se alinea con una estructura ágil y flexible en el proceso de toma de decisiones, ante un escenario de grandes cambios y múltiples demandas, yendo más allá de los conceptos básicos de la gestión universitaria; 4) hubo una interrelación explicita entre la gobernanza universitaria y los rankings académicos, que se consideran herramientas de gobernanza importantes cuando las universidades las consideran en su planificación estratégica para superar las debilidades identificadas.

Palabras clave: Gobernanza universitaria. Rankings académicos. Educación universitaria.

Recebido em 1 de setembro de 2019

Aceito em 15 de outubro de 2020

\section{INTRODUÇÃO}

A governança universitária está relacionada aos atores que detém e exercem poder de decisão no contexto das universidades. Dada as particularidades de uma universidade, este processo é complexo, no entanto, essencial (BRUNNER 2011). Analisando as tipologias, conceitos e tendências da governança universitária, Brunner (2011) afirma que este fenômeno, se refere à maneira pela qual as universidades são organizadas e operadas internamente e às suas relações com entidades externas, com vistas a assegurar os objetivos do ensino superior para que melhorem os diversos aspectos que envolvem a tomada de decisão. № entendimento deste autor, a governança universitária estaria relacionada com a capacidade de adaptação das universidades às contínuas mudanças das demandas do entorno, no qual estão inseridas e as transformações estruturais do mesmo.

A emergência dos rankings acadêmicos - nacionais e internacionais - é um fenômeno que vem ganhando proeminência e tornado presente na realidade das universidades brasileiras com indicativos de implicações diretas para a governança universitária (CALDERÓN; WANDERCIL; MARTINS, 2019; WANDERCLL; CALDERÓN; GANGA-CONTRERAS, 2019; WANDERCIL; CALDERÓN, 2020). Apesar de não haver consenso sobre diversos aspectos que envolvem este fenômeno, os rankings desencadearam um movimento, em diversas universidades brasileiras, 
no sentido de buscarem conhecer melhor suas metodologias, indicadores e o processo de sistematização dos resultados.

Embora seja evidente a imbricada relação entre rankings acadêmicos e governança universitária ainda é muito tímida, na realidade latino-americana, a produção científica que se debruça sobre a temática em questão. Este fato é tão certo que nas principais bases de dados somente encontra-se como artigo único e pioneiro, o estudo de Fanelli e Carranza (2018), no qual a partir da experiência internacional, as autoras analisam os principais usos dos rankings acadêmicos dentro da estrutura de governança universitária, enfocando como os rankings afetam o processo decisório dos agentes internos e externos às instituições universitárias.

No estudo intitulado 'Governança: conceitos e emergências na educação brasileira', Santos et al. (2016) afirmam que a literatura sobre a governança universitária no Brasil é uma questão atual e passou a ser investigada a partir de 2010, ou seja, há menos de uma década. Os dados revelam que o tema é pouco discutido, Sartori (2011) afirma que há poucas pesquisas no país que abordam esse fenômeno e, segundo Sassaki (2014), grande parte da literatura a respeito da temática é desenvolvida nos Estados Unidos e Europa.

Se por um lado, no Brasil a literatura acadêmica sobre governança universitária ainda é incipiente, por outro, o mesmo não se pode afirmar em relação à literatura iberoamericana e do mundo anglo-saxão, na qual é evidente a preocupação teórica da comunidade acadêmica internacional em torno de temática fundamental na vida das instituições universitárias (BRUNNER, 2011; BRUNNER; GANGA CONTRERAS, 2016; FANELLI; CARRANZA, 2018).

Nesse contexto, o presente estudo tem como objetivo traçar e analisar o estado da questão na literatura acadêmica brasileira sobre a Governança Universitária e sua inter-relação com os rankings acadêmicos com o intuito de identificar as tendências predominantes, tendo como referência três indicadores analíticos: conceito, metodologia e bases epistemológicas. 0 esquema organizado na Figura 1 representa a estrutura de análise realizada neste artigo sobre governança universitária e rankings acadêmicos à luz da literatura científica brasileira. 
Figura 1 - Estrutura analítica do processo de elaboração do presente artigo

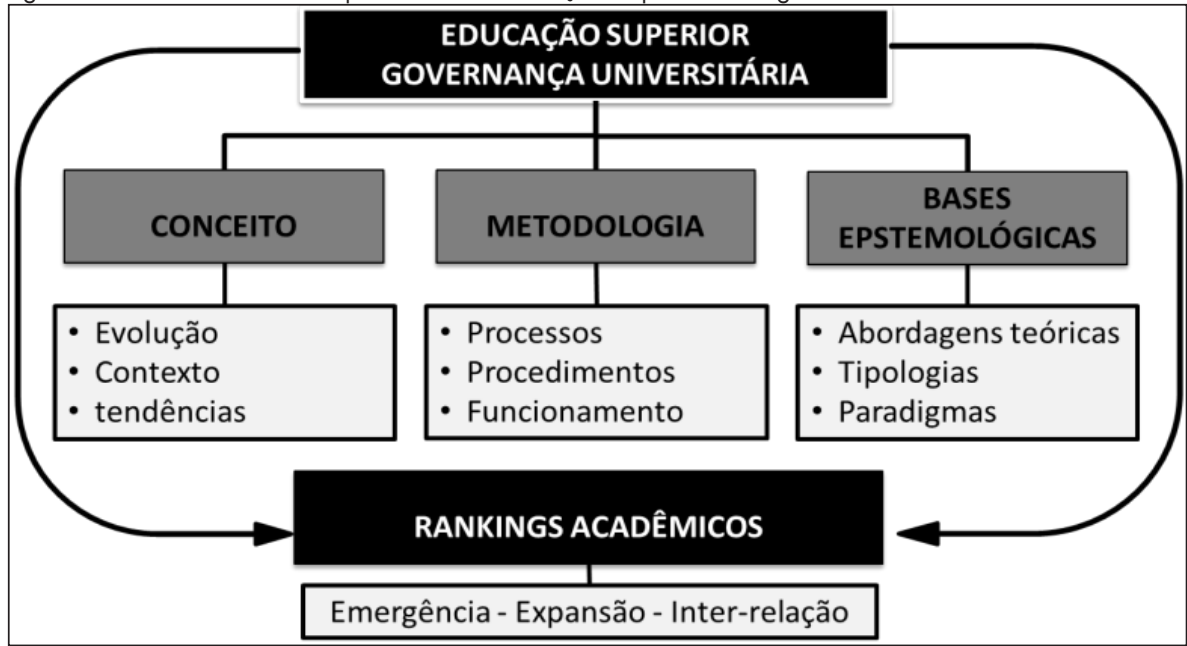

Fonte: os autores.

Como se observa na Figura 1, nos aspectos conceituais se toma como referência três processos que permitem sua articulação e sustentação, evolução, contextos e tendências. Nos aspectos metodológicos se enfatizam processos, procedimentos e funcionamento. Já nas bases epistemológicas englobam-se abordagens teóricas, tipologias e paradigmas norteadores da literatura analisada.

A finalidade de estudos bibliográficos do tipo estado da questão é, conforme Therrien e Nóbrega-Therrien (2004, p. 7), "levar o pesquisador a registrar, a partir de um rigoroso levantamento bibliográfico, como se encontra o tema ou o objeto de sua investigação no estado atual da ciência ao seu alcance." Para alcançar essa finalidade, neste artigo, o levantamento bibliográfico tomou como referência um conjunto de estudos, aqui denominados como literatura científica brasileira, englobados entre artigos científicos, teses e dissertações disseminados em bases de dados brasileiras, sendo que doravante estas duas últimas formas de produção científica serão chamadas de teses acadêmicas. Trata-se de uma literatura considerada como conhecimento científico certificado, isto é, cientificamente validado por meio de "formas em que a ciência tem concebido normas consensuais de codificação e divulgação de novo conhecimento." (OROzCO; CHAVARRO, 2010, p. 147).

Assim, o corpus analítico foi levantado junto ao Catálogo de Teses da Coordenação de Aperfeiçoamento de Pessoal de Nível Superior (CAPES), fundação vinculada ao Ministério da Educação (MEC) do Brasil; ao Portal de Periódicos da CAPES; à Base de Dados Educ@ Publicações online de educação da Fundação Carlos Chagas (FCC) e ao acervo da Rede Brasileira de Pesquisa em Rankings, Índices e Tabelas Classificatórias na Educação Superior (REDE 
RANKINTACS). Os descritores que nortearam o levantamento bibliográfico foram governança universitária e governança universitária + rankings acadêmicos, os quais deveriam constar no título dos buscadores e/ou no assunto da pesquisa. A definição desse critério justifica-se pela necessidade de tornar a busca mais objetiva, uma vez que existe uma diversidade de publicações sobre o tema voltado para atividades fora do âmbito da educação superior, e ainda pela necessidade de identificar publicações que apresentassem contribuições teóricas sobre a governança universitária, no uso específico do termo. 0 corpus de análise contempla: três teses acadêmicas (uma dissertação, duas teses) e três artigos científicos, fato que revela o ainda inexplorado campo de estudos existente sobre as temáticas em questão.

Quadro 1 - Produção científica brasileira sobre governança universitária classificada por área do conhecimento, tipo de produção, ano de publicação, instituição ou periódico científico, nome do autor e título da produção

\begin{tabular}{|l|l|l|l|l|l|}
\hline \multicolumn{1}{|c|}{$\begin{array}{c}\text { Área de } \\
\text { conhecimento }\end{array}$} & $\begin{array}{c}\text { Tipo de } \\
\text { produção } \\
\text { acadêmica }\end{array}$ & Ano & $\begin{array}{l}\text { Instituição / } \\
\text { Periódico }\end{array}$ & \multicolumn{1}{|c|}{ Autor } & \multicolumn{1}{c|}{ Título } \\
\hline Interdisciplinar & $\begin{array}{l}\text { Dissertação } \\
\text { Mestrado }\end{array}$ & 2007 & UNIJUl & Parnoff & $\begin{array}{l}\text { 0 Processo Decisório em uma Burocracia } \\
\text { Profissional - Implicações Políticas e Racio- } \\
\text { nalidade Administrativa - o caso da UNIJUI. }\end{array}$ \\
\hline $\begin{array}{l}\text { Sociais e } \\
\text { Humanidades }\end{array}$ & $\begin{array}{l}\text { Tese } \\
\text { Doutorado }\end{array}$ & 2014 & UFRJ & Barros & $\begin{array}{l}\text { O modelo brasileiro de governança } \\
\text { acadêmica e seus efeitos na produtividade } \\
\text { científica }\end{array}$ \\
\hline $\begin{array}{l}\text { Administração } \\
\text { de Empresas }\end{array}$ & $\begin{array}{l}\text { Tese } \\
\text { Doutorado }\end{array}$ & 2016 & USP & Sassaki & $\begin{array}{l}\text { Governança e conformidade na gestão } \\
\text { universitária }\end{array}$ \\
\hline Multidisciplinar & $\begin{array}{l}\text { Artigo } \\
\text { Científico }\end{array}$ & 2016 & Holos & $\begin{array}{l}\text { Félix E } \\
\text { Furtado }\end{array}$ & $\begin{array}{l}\text { Autoavaliação Institucional e (ln)Cultura de } \\
\text { Participação na Universidade }\end{array}$ \\
\hline $\begin{array}{l}\text { Ciências } \\
\text { Sociais }\end{array}$ & $\begin{array}{l}\text { Artigo } \\
\text { Científico }\end{array}$ & 2017 & Sociologias & Balbachevsky & $\begin{array}{l}\text { Governança na pesquisa científica: reflexões } \\
\text { sobre a prática da pesquisa contemporâ- } \\
\text { nea e a experiência brasileira }\end{array}$ \\
\hline $\begin{array}{l}\text { Artigo } \\
\text { Científico }\end{array}$ & 2018 & $\begin{array}{l}\text { Educação e } \\
\text { Sociedade }\end{array}$ & $\begin{array}{l}\text { Klein; Pizzio e } \\
\text { Rodrigues. }\end{array}$ & $\begin{array}{l}\text { Governança Universitária e Custos de } \\
\text { Transação nas Universidades da Amazônia } \\
\text { Legal Brasileira }\end{array}$ \\
\hline
\end{tabular}

Fonte: Capes (2018a, 2018b).

A literatura científica levantada permitiu verificar a recente trajetória das pesquisas desenvolvidas sobre o tema governança universitária. A primeira produção data do ano de 2007, com um intervalo de sete anos para a então retomada da discussão, ou seja, somente nos últimos quatro anos é que as pesquisas passaram a configurar mais efetivamente o debate acadêmico: uma produção em 2014, duas em 2016, uma, 2017 e outra, em 2018, conforme demonstrado no Quadro 1. 
As obras identificadas estão distribuídas em duas grandes áreas do conhecimento, Ciências Humanas e Ciências Sociais Aplicadas (duas, são das ciências sociais, uma, da educação, uma, da administração de empresas, uma com foco multidisciplinar e outra com foco na interdisciplinaridade). Ainda que, apenas duas áreas do conhecimento tenham sido abrangidas, os pesquisadores fundamentaram suas pesquisas em autores de diferentes áreas do conhecimento e bases epistemológicas.

Quadro 2 - Produção científica brasileira sobre rankings acadêmicos

\begin{tabular}{|c|c|c|c|c|c|}
\hline \multicolumn{2}{|c|}{$\begin{array}{c}\text { Área de } \\
\text { conhecimento }\end{array}$} & Ano & Instituição & Autor & Título \\
\hline \multirow{6}{*}{$\begin{array}{l}\frac{8}{0} \\
\frac{0}{0} \\
\text { के } \\
\sum\end{array}$} & $\begin{array}{l}\text { Administração } \\
\text { em Gestão } \\
\text { Internacional }\end{array}$ & 2004 & ESPM & Vieira & $\begin{array}{l}\text { A internacionalização da pós-graduação no Brasil: } \\
\text { a relação entre os rankings acadêmicos globais e } \\
\text { avaliação dos programas de pós-graduação em } \\
\text { Administração }\end{array}$ \\
\hline & $\begin{array}{l}\text { Engenharia } \\
\text { de Produção }\end{array}$ & 2014 & UFRGS & Beuren & $\begin{array}{l}\text { Avaliação da qualidade institucional através de rankin- } \\
\text { gs nacionais e internacionais }\end{array}$ \\
\hline & Educação & 2014 & $\begin{array}{l}\text { PUC- } \\
\text { Campinas }\end{array}$ & Lourenço & $\begin{array}{l}\text { Os rankings do Guia do Estudante na educação } \\
\text { superior brasileira: um estudo sobre as estratégias de } \\
\text { divulgação adotadas pelas instituições que obtiveram o } \\
\text { Prêmio Melhores Universidades }\end{array}$ \\
\hline & Educação & 2015 & $\begin{array}{l}\text { PUC-Cam- } \\
\text { pinas }\end{array}$ & França & $\begin{array}{l}\text { Rankings universitários promovidos por jornais no es- } \\
\text { paço lbero-Americano: El Mundo (Espanha), El Mercurio } \\
\text { (Chile) e Folha de São Paulo (Brasil) }\end{array}$ \\
\hline & $\begin{array}{l}\text { Relações } \\
\text { Internacionais }\end{array}$ & 2015 & USP & Axel-Berg & $\begin{array}{l}\text { Competindo no cenário mundial: a Universidade de São } \\
\text { Paulo e o ranking global de universidades }\end{array}$ \\
\hline & Administração & 2016 & UFPE & Silva & $\begin{array}{l}\text { A governança nas instituições de ensino superior: o } \\
\text { caso da Universidade Federal de Pernambuco }\end{array}$ \\
\hline \multirow{3}{*}{$\begin{array}{l}\frac{0}{0} \\
\frac{0}{0} \\
\text { गे } \\
0\end{array}$} & $\begin{array}{l}\text { Ciência da } \\
\text { Informação }\end{array}$ & 2015 & USP & Santos & $\begin{array}{l}0 \text { desempenho das universidades brasileiras nos } \\
\text { rankings internacionais: áreas de destaque da produ- } \\
\text { ção científica brasileira }\end{array}$ \\
\hline & $\begin{array}{l}\text { Política } \\
\text { Científica e } \\
\text { Tecnológica }\end{array}$ & 2016 & UNICAMP & Righetti & $\begin{array}{l}\text { Qual é a melhor? origem, indicadores, limitações e } \\
\text { impactos dos rankings universitários }\end{array}$ \\
\hline & Educação & 2018 & UFSC & Thiengo & $\begin{array}{l}\text { Universidades de Classe Mundial e o Consenso pela } \\
\text { Excelência: Tendências e Manifestações Globais e } \\
\text { Locais. }\end{array}$ \\
\hline
\end{tabular}

Fonte: Rede Rankintacs (2018).

No levantamento sobre a literatura científica em torno da temática rankings acadêmicos (Quadro 2), para análise de possível inter-relação com a governança universitária, 
identificaram-se oito teses acadêmicas (seis dissertações e três teses). Das seis dissertações duas foram desenvolvidas na área da educação, três na área de administração e uma no âmbito da Engenharia de Produção. Das três teses uma foi defendida na área da Ciência da Informação, outra em Política Científica e Tecnológica e, a terceira, na área da Educação. Essa diversidade de áreas de conhecimento revela que a temática rankings acadêmicos tornou-se essencialmente multidisciplinar.

\section{GOUERNANÇA UNIUERSITÁRIA À LUZ DAS TESES ACADÊMICAS}

0 corpus analítico das teses acadêmicas específicas sobre governança universitária, foi constituído de uma dissertação e duas teses. Apesar das mesmas serem de áreas diferentes (Quadro 1), verificou-se a partir dos dados coletados na Plataforma Lattes $^{5}$ que os orientadores dos autores das teses e os próprios autores são de áreas de formação como Administração, História e Biblioteconomia, cursos oriundos de duas grandes áreas do conhecimento, as Ciências Humanas e as Sociais Aplicadas, cujos campos de formação possuem vieses multi e interdisciplinar. 0 Quadro 3 relaciona as linhas de pesquisas dos orientadores das teses acadêmicas, área de conhecimento dos autores e a área de concentração onde foram defendidas as referidas teses.

Quadro 3 - Teses acadêmicas sobre governança universitária. Orientadores das teses acadêmicas, suas linhas de pesquisa, incluindo autores das teses, suas áreas de conhecimento e áreas de concentração das teses acadêmicas

\begin{tabular}{|c|c|c|c|c|}
\hline Orientador & Linha de pesquisa & Autor & $\begin{array}{c}\text { Área de } \\
\text { conhecimento }\end{array}$ & Área de concentração \\
\hline $\begin{array}{l}\text { Jorge Oneide } \\
\text { Sausen }\end{array}$ & $\begin{array}{l}\text { Gestão de Organiza- } \\
\text { ções para o Desenvol- } \\
\text { vimento. }\end{array}$ & Parnoff & Administração & $\begin{array}{l}\text { Mestrado em Desenvolvimento - Inter- } \\
\text { disciplinar }\end{array}$ \\
\hline $\begin{array}{l}\text { Mércio Go- } \\
\text { mes Pereira }\end{array}$ & $\begin{array}{l}\text { História das Ciências, } \\
\text { das Técnicas e Episte- } \\
\text { mologia. }\end{array}$ & Barros & Biblioteconomia & $\begin{array}{l}\text { Doutorado em História das Ciências e } \\
\text { das Técnicas e Epistemologia - Sociais } \\
\text { e Humanidades }\end{array}$ \\
\hline $\begin{array}{l}\text { Jacques } \\
\text { Marcovitch }\end{array}$ & $\begin{array}{l}\text { Ciências Sociais } \\
\text { Aplicadas. }\end{array}$ & Sassaki & Administração & $\begin{array}{l}\text { Doutorado em Administração - Adminis- } \\
\text { tração de Empresas }\end{array}$ \\
\hline
\end{tabular}

Fonte: CNPq (2018).

\footnotetext{
A Plataforma Lattes é um banco de dados online com os currículos dos pesquisadores brasileiros. Criado e mantido pelo Conselho Nacional de Desenvolvimento Científico e Tecnológico (CNPq) do Ministério da Ciência, Tecnologia, Inovações e Comunicações do Brasil.
} 
Parnoff (2007) não enveredou sua análise para o desdobramento do conceito da terminologia em questão, direcionando-a para a compreensão dos "modelos de governança universitária" (burocrático-racional, colegial, político e anarquia organizada) que se evidenciaram no contexto de uma universidade privada sem fins lucrativos no sul do país. 0 processo de governança universitária, segundo Parnoff (2007), sofre influências políticas e administrativas, uma vez que, na medida em que as instâncias decisórias são constituídas por pessoas de diferentes áreas do conhecimento, essas pessoas possuem interesses distintos. Nessa linha analítica, o autor descreve os níveis decisórios no ambiente universitário, tendo como referência teórica a pesquisa de Hardy e Fachin (2000), que apresentam os modelos de governança universitária com as seguintes variáveis nos processos de tomada de decisão: autonomia; responsabilidade; complexidade; limitações; poder de decisão - grau de impacto; capacidade de julgamento profissional; participação e comprometimento; embasamento - motivação; dependência/independência e; adesão, nos níveis estratégico, gerencial e operacional. Os modelos de governança universitária, evidenciados, mudam de acordo com a variável preponderante nos níveis estratégico, gerencial e operacional.

Barros (2014) faz um delineamento do panorama nacional da governança universitária, sob o prisma da ética acadêmica, a fim de compreender os processos promotores das relações institucionais fundamentais na atividade científica e, em certa medida, dada pela valorização da publicação de artigos em periódicos bem classificados, como premissa para obtenção de melhores cargos e salários nas universidades brasileiras (destaque e prestígio). De acordo com o autor, a valorização de publicações em periódicos científicos de alto impacto tem determinado um modelo de governança que oferece apoio para a realização das atividades de pesquisa, exigindo de seu corpo docente-pesquisador, estímulos e incentivos para gerarem produtos científicos, tendo como contrapartida, um nível de produtividade satisfatório, dentro de um aparato de publicação acadêmica que dissemina a parte mais canônica desses produtos, os artigos científicos, servindo em grande parte como certificador de excelência acadêmica e parâmetro para recompensas ao trabalho realizado. Entretanto, Barros (2014) assinala que o preço praticado por grandes editoras acaba sendo inacessível para alguns docentes, pois,

Recentes críticas às grandes editoras científicas comerciais são fortes indicativos da insatisfação de muitos acadêmicos com o modelo comercial da comunicação científica atual. [...] é prática comum em algumas áreas que periódicos científicos cobrem taxas na entrada, pela publicação de artigos originais, e na saída, pelo acesso aos artigos publicados, em suas versões impressas ou digitais. Outro efeito é o preço da publicação, pois em uma lógica tipicamente de mercado, quanto maior a demanda e menor a oferta (periódicos com alto $\mathrm{Fl} \mathrm{e/ou} \mathrm{bem} \mathrm{classificados),} \mathrm{maior} \mathrm{o} \mathrm{preço} \mathrm{da} \mathrm{mercadoria.}$ (BARROS, 2014, p. 57). 
Essa dinâmica de carreira acadêmica envolve fatores intrínsecos, tais como "o incremento na autoria de artigos publicados em periódicos científicos", e extrínsecos, como o "desenvolvimento de políticas de fomento e o impacto financeiro das crises econômicas sobre a governança universitária" (BARROS, 2014, p.10). Os fatores extrínsecos apontados por Barros (2014) vêm ao encontro do estudo de Sassaki (2016), que tendo como respaldo estudos sobre governança universitária, compliance ${ }^{6}$ e teoria de sistemas, ${ }^{7}$ tendo como objetivo estudar a crise do desequilíbrio financeiro da Universidade de São Paulo (USP) causado pela ampliação de gastos no período de 2010 a 2013. Sassaki (2016) registrou como causa dessa crise, o aumento dos gastos plurianual, especialmente relacionados a remuneração de servidores, bem como, a instituição de Prêmio de Excelência Acadêmica institucional da USP (UNIVERSIDADE DE SÃO PAULO, 2008), o mesmo que intensificado em 2012 e extinto em 2014, numa tentativa de bonificação pela performance em rankings internacionais que fracassou devido à crise financeira institucional desta universidade (CALDERÓN, 2017). Além de analisar um período crítico para a USP, Sassaki (2016) apresentou também um conjunto de sugestões e recomendações no sentido de aperfeiçoar os processos de governança universitária, sendo uma delas a criação de indicadores e parâmetros de sustentabilidade financeira. Outra sugestão, foi a de subsidiar os conselhos superiores da universidade com informações dos efetivos e reais impactos plurianuais das decisões tomadas, pois, segundo o autor, grande parte de seus membros não possuem formação gerencial, mas que poderiam tomar decisões mais eficazes, caso tivessem munidos de relatórios gerenciais estabelecidos por meio de um sistema de governança universitária.

Das três teses acadêmicas, a pesquisa de Barros (2014) é a única que apresenta uma proposta de um modelo de governança universitária que aborda a gestão do conhecimento, no sentido de seguir os melhores preceitos de comportamento éticoacadêmico, alinhado a uma sequência de atividades relacionadas à publicação científica e sua interrelação com os órgãos de regulação, uma vez que a "produção científica encarada como moeda de troca é representada também por meio da governança universitária, que toma por base alguns critérios para avaliação, contratações e promoções de carreira." (BARROS, 2014, p. 50). 0 autor se fundamenta nos estudos de Robert Merton (1979), para quem "o número de publicação dos cientistas não são ofertas livremente dadas, e sim serviços em troca de um salário." (BARROS, 2014, p. 50).

Convêm destacar que nos esforços teóricos de Parnoff (2007) e Sassaki (2016) se evidenciam modelos de governança universitária fundamentados no livro "Gestão Estratégica

6 Compliance é uma ação interna da empresa voltada a garantir que o negócio se mantenha dentro das regras estabelecidas pelos órgãos reguladores e em consonância com o próprio regulamento interno da companhia.

70 conceito de sistema proporciona uma visão compreensiva, abrangente, holística las totalidades representam mais que a soma de suas partes) e gestáltica (o todo é maior que a soma das partes) de um conjunto de coisas complexas, dando $\square$ lhes uma configuração e identidade total (CHIAVENAT0, 1998). 
na Universidade Brasileira: Teoria e Casos" de Hardy e Fachin (2000), obra que pode ser considerada como principal referencial teórico nessas teses acadêmicas. A partir desse livro, Parnoff (2007) e Sassaki (2016) fundamentaram suas pesquisas em quatro modelos de governança: burocrático-racional, colegial, político e anarquia organizada (Quadro 4), alinhados aos processos de governança universitária de dois casos específicos, a Universidade Regional do Noroeste do Estado do Rio Grande do Sul (UNIJUÍ) e a USP, respectivamente.

Quadro 4 - Modelos de governança universitária

\begin{tabular}{|c|c|}
\hline Modelo & Abordagens Teóricas \\
\hline Burocrático & $\begin{array}{l}\text { - Hierarquia de autoridade claramente definida com três ou mais níveis de autoridade. } \\
\text { - Regras e normas reguladoras de todos os órgãos universitários, uma composição e } \\
\text { - Atos, decisões e regras registradas em estatutos e regulamentos gerais e específicos. } \\
\text { - Especialização por área de conhecimento - divisão do trabalho de direção e de execução. } \\
\text { - Seleção a cargo diretivo e docente, com base nas qualificações técnicas de provas e títulos. } \\
\text { - Promoção em conformidade com a realização acadêmica e tempo de serviço na instituição. }\end{array}$ \\
\hline Político & $\begin{array}{l}\text { - } 0 \text { conflito é natural e deve ser esperado em qualquer organização complexa. } \\
\text { - Blocos de poder e grupos de interesse que esforçam para garantir seus valores e metas. } \\
\text { - Muitas das principais decisões são controladas por pequenos grupos da elite do poder. } \\
\text { - Tendência democrática é similar e da sociedade em que está inserida. } \\
\text { - Pressão política e interesses ultrapassam limites da autoridade formal do sistema } \\
\text { burocrático. }\end{array}$ \\
\hline Colegiado & $\begin{array}{l}\text { - Os acadêmicos têm tendências a não se submeterem ao processo hierarquizado da } \\
\text { burocracia. } \\
\text { - A participação da comunidade acadêmica nas tomadas de decisão é temporária. } \\
\text { - Comunidade docente tende administrar seu trabalho, por meio da autoridade profissional. } \\
\text { - Os funcionários burocratas tendem a administrar com menor influência. } \\
\text { - As decisões são tomadas por consenso. } \\
\text { - } 0 \text { docente é tecnicamente competente para tomar as próprias decisões. }\end{array}$ \\
\hline $\begin{array}{l}\text { Anarquia } \\
\text { organizada }\end{array}$ & $\begin{array}{l}\text { - As universidades possuem objetivos vagos, ambíguos e muitas vezes conflitantes. } \\
\text { - } \text { Profissionais requerem autonomia na execução de tarefas e participação no processo } \\
\text { - } \text { Tecnologia utilizada difusa, não estabelecendo rotinas, prevalece atendimento individualizado. } \\
\text { - } \quad \text { Comunidade atendida necessidades diferenciadas e com participação no processo decisório. } \\
\text { - } \text { Os gestores universitários não planejam. Organização centrada em órgãos colegiados. } \\
\text { - Decisões não definitivas, problema acaba retornando várias vezes aos órgãos colegiados. }\end{array}$ \\
\hline
\end{tabular}

Fonte: adaptado de Parnoff (2007) e Sassaki (2016).

Em relação ao Quadro 4 deve-se considerar que a consolidação das abordagens teóricas evidenciadas nos modelos de governança universitária sinaliza "uma perspectiva 
parcial e incompleta da prática e realidade no ambiente universitário, mas, conjuntamente, permitem uma visão combinada e complementar." (SASSAKI, 2016, p. 39).

Embora, poucas foram as assertivas identificadas nas teses acadêmicas discorrendo a respeito do conceito de governança universitária, a partir da leitura desses estudos, pôde-se fazer duas inferências que acenam para duas formas de compreender a governança universitária. Para Parnoff (2007) e Sassaki (2016), a governança universitária tem a ver com estruturas de representação do poder para tomada de decisão, e esse fenômeno sofre influências políticas e administrativas, uma vez que, na medida em que as instâncias decisórias são constituídas por pessoas de diferentes áreas do conhecimento e com interesses distintos, este cenário, muitas vezes é entendido como arenas de interação entre os diversos stakeholders que adotam diferentes estratégias para atingir seus objetivos. Por sua vez, Barros (2014) compreende a governança universitária como a gestão das atividades científicas, no contexto dos efeitos das relações institucionais e incentivos para a realização das atividades de pesquisa e gestão do conhecimento dentro dos melhores preceitos de comportamento social.

\section{GOUERNANÇA UNIUERSITÁRIA À LUZ DOS ARTIGOS CIENTÍFICOS}

Três artigos científicos compõem o corpus de análise deste subtítulo, um artigo publicado em periódico da área da Educação, outro de área Multidisciplinar e um terceiro da área da Ciências Sociais (Quadro 5).

Quadro 5 - Artigos científicos publicados em periódicos brasileiros sobre governança universitária. Dados do periódico (Nome e área de conhecimento), dados dos autores (nome e área de atuação) e títulos dos artigos

\begin{tabular}{|c|c|c|c|c|}
\hline \multicolumn{2}{|c|}{ Dados do periódico } & \multicolumn{2}{|c|}{ Dados dos autores } & \multirow[b]{2}{*}{ Título } \\
\hline Nome & $\begin{array}{c}\text { Área de } \\
\text { conhecimento }\end{array}$ & Nome & $\begin{array}{l}\text { Área de } \\
\text { atuação }\end{array}$ & \\
\hline \multirow{2}{*}{ Holos } & \multirow{2}{*}{ Multidisciplinar } & $\begin{array}{l}\text { Glades Tereza } \\
\text { Félix }\end{array}$ & Educação & \multirow{2}{*}{$\begin{array}{l}\text { Autoavaliação Institucional e (In)Cultura de } \\
\text { Participação na Universidade }\end{array}$} \\
\hline & & $\begin{array}{l}\text { Daniele B. V. } \\
\text { Furtado }\end{array}$ & Educação & \\
\hline Sociologias & $\begin{array}{l}\text { Ciências } \\
\text { Sociais }\end{array}$ & $\begin{array}{l}\text { Elizabeth } \\
\text { Balbachevsky }\end{array}$ & $\begin{array}{l}\text { Sociologia e } \\
\text { Educação }\end{array}$ & $\begin{array}{l}\text { Governança na pesquisa científica: } \\
\text { reflexões sobre a prática da pesquisa } \\
\text { contemporânea e a experiência brasileira }\end{array}$ \\
\hline
\end{tabular}




\begin{tabular}{|c|c|c|c|c|}
\hline \multicolumn{2}{|c|}{ Dados do periódico } & \multicolumn{2}{|c|}{ Dados dos autores } & \multirow[b]{2}{*}{ Título } \\
\hline Nome & $\begin{array}{l}\text { Área de } \\
\text { conhecimento }\end{array}$ & Nome & $\begin{array}{l}\text { Área de } \\
\text { atuação }\end{array}$ & \\
\hline \multirow{3}{*}{$\begin{array}{l}\text { Educação e } \\
\text { Sociedade }\end{array}$} & \multirow{3}{*}{ Educação } & Karla Klein & $\begin{array}{l}\text { Psicologia } \\
\text { Organizacional }\end{array}$ & \multirow{3}{*}{$\begin{array}{l}\text { Governança Universitária e Custos de } \\
\text { Transação nas Universidades da Amazônia } \\
\text { Legal Brasileira }\end{array}$} \\
\hline & & Alex Pizzio & Sociologia & \\
\hline & & $\begin{array}{l}\text { Waldecy } \\
\text { Rodrigues }\end{array}$ & Economia & \\
\hline
\end{tabular}

Fonte: Capes (2018b) e CNPq (2018).

Félix e Furtado (2016), em seu artigo, demonstra o desafio para a governança universitária no âmbito das políticas públicas, ao abordarem a relação entre avaliação interna e a intensidade de participação da comunidade universitária. Félix e Furtado (2016) afirmam que, no caso brasileiro, há uma crise nas instituições públicas de educação gerada na relação delas com o Estado, evidenciando que a educação superior é um dos campos cujo domínio é objeto da mais acirrada disputa política. Para Félix e Furtado (2016) as ações burocráticas dos processos regulatórios de avaliação acabam gerando problemas de ordem política, esses problemas têm sido o principal desafio para a governança universitária, pois dificultam a implantação e consolidação de uma cultura de avaliação. Para Félix e Furtado (2016) a superação de tais problemas, se dão por meio da governança universitária alinhada a qualidade da participação, para contribuam para que a instituição possa elaborar seu próprio projeto de autoavaliação, a partir do envolvimento da comunidade e não apenas cumprindo uma consulta para alimentar dados para a supervisão do Estado regulador.

Na mesma linha de Sassaki (2016), Félix e Furtado (2016) afirmam que as organizações universitárias são arenas políticas que apresentam lutas constantes pelo poder para tomada de decisão, com o objetivo de acesso e controle a recursos reais e/ou simbólicos e que os membros das organizações são atores políticos com suas demandas, estratégias e táticas. As autoras demonstram a importância da participação de todos os atores envolvidos (stakeholders) no processo de autoavaliação institucional, revelando ser esse, também, um desafio para a governança universitária que bem conduzida, pode contribuir para minimizar os entraves e problemas e agir em favor da construção de uma cultura permanente de avaliação na universidade.

Ao encontro da contribuição acadêmica de Barros (2014), a questão central do artigo de Balbachevsky (2017) foi de investigar a interação entre as mudanças experimentadas na governança universitária, as alterações recentes no modo de produção do conhecimento, e os novos modelos de governança da ciência. Balbachevsky (2017), afirma que, independente das pressões externas, para a reconfiguração do modo de produção do conhecimento, as tensões refletem no modelo de governança das ciências e das universidades, pois "ciência 
e academia ocupam o mesmo espaço institucional: embora a pesquisa científica possa se organizar em outros espaços sociais, é inegável que, em todo o mundo, o ambiente acadêmico é o espaço privilegiado para a organização coletiva da ciência." (BALBACHEVSKY, 2017, p. 78).

Em países que ocupam lugar de destaque na produção do conhecimento científico, a universidade experimentou reformas profundas nas três últimas décadas e, segundo Balbachevsky (2017), a literatura internacional converge para o diagnóstico de que essas reformas focam o modelo de governança das universidades alinhadas à governança da ciência.

Esse formato de governança assume que o conhecimento científico é um bem público que deve ter acesso irrestrito, e vem ao encontro do conceito alinhado ao paradigma mertoniano de universalismo e comunismo (ou comunalismo) da ciência que diz respeito à norma que defende a socialização das descobertas e dos produtos científicos, a busca de conhecimento de forma coletiva, resultante da colaboração social tendo o conhecimento como propriedade coletiva (MERTON, 1979). Esse modo de governança da ciência, apresentado por Balbachevsky (2017), estabelece que a ciência precisa se desenvolver dentro de linhas disciplinares como condição para controle da qualidade exercido por comunidades de pares fortemente conectadas e ao conhecimento científico certificado.

Os artigos científicos revelam que, tanto Balbachevsky (2017) quanto Klein, Pizzio e Rodrigues (2018), analisam a tipologia de IES e suas dinâmicas de governança, tomando como referência as contribuições do livro "University Dynamics and European Integration" escrito por Olsen e Maassen (2007), autores que distinguem quatro diferentes modelos: humboltiano, instrumental, democrático e Empreendedor, consolidados no Quadro 6.

Quadro 6 - Consolidação das tipologias/modelos e suas dinâmicas de governança

\begin{tabular}{|c|c|}
\hline Modelos & Características \\
\hline Humboltiano & $\begin{array}{l}\text { - Caracterizado por uma forte convergência de valores que sustentam fortes hierarquias } \\
\text { de autoridade dentro da instituição. } \\
\text { - Supõe que a liderança científica está completamente alinhada à liderança institucional } \\
\text { e que as dinâmicas da produção do conhecimento se organizam dentro de fronteiras } \\
\text { disciplinares claras e conhecidas. } \\
\text { - As interações da universidade com o ambiente externo respondem a uma agenda que é } \\
\text { negociada no interior da instituição. }\end{array}$ \\
\hline Instrumental & $\begin{array}{l}\text { - Corresponde à universidade estatal, criada para responder a uma missão específica } \\
\text { atribuída pelo Estado. } \\
\text { - A lógica administrativa tende a predominar, as dinâmicas internas da instituição são } \\
\text { fortemente condicionadas e respondem às decisões tomadas no âmbito do Estado. } \\
\text { - } 0 \text { modelo histórico que mais se aproxima desse ideal é o das universidades criadas pelos } \\
\text { Estados socialistas do século passado e está presente na experiência chinesa dos dias } \\
\text { atuais. }\end{array}$ \\
\hline
\end{tabular}




\begin{tabular}{|c|c|}
\hline Moc & Características \\
\hline Democrático & $\begin{array}{l}\text { - A autoridade se legitima porque é uma representação dos diferentes interesses } \\
\text { presentes na instituição. } \\
\text { - As dinâmicas da instituição respondem basicamente aos interesses dos diferentes } \\
\text { setores internos que se fazem presentes no processo eleitoral. } \\
\text { - As interações da universidade com o ambiente externo respondem a uma agenda que é } \\
\text { negociada no interior da instituição. }\end{array}$ \\
\hline Empreendedor & $\begin{array}{l}\text { - Instituição imersa num ambiente marcado pela competição, e suas subunidades } \\
\text { submetidas à mesma lógica competitiva, estimuladas a explorar as oportunidades abertas } \\
\text { no ambiente externo e interno. } \\
\text { - As oportunidades e riscos presentes nesse ambiente são o fator que mais claramente } \\
\text { definem a trajetória de cada instituição. } \\
\text { - A experiência que mais se aproxima desse tipo ideal é a grande universidade de pesquisa } \\
\text { norte-americana. }\end{array}$ \\
\hline
\end{tabular}

Fonte: adaptado de Balbachevsky (2017) e Klein, Pizzio e Rodrigues (2018), que adotaram os modelos teóricos estabelecidos por Olsen e Maassen (2007).

De acordo com o referencial apontado (BALBACHEVSKY, 2017; KLEIN; PIZZIO; RODRIGUES, 2018), a tipologia da governança da universidade pública brasileira é organizada sob a lógica da representação de interesses, onde a consulta com a participação de todos os setores, é o mecanismo reconhecido e legitimado para se definir o controle da instituição. Segundo Balbachevsky (2017), mesmo no setor privado, a legitimidade do modelo democrático (Quadro 6) é forte e tende a se reproduzir, em maior ou menor grau na maioria das $\mathbb{E} E$ sem fins lucrativos do tipo comunitárias, sendo que, para que o princípio representativo dominante, as decisões para serem legítimas, devem ser negociadas junto aos interesses internos à instituição.

A pesquisa de Klein, Pizzio e Rodrigues (2018) lança um olhar sobre a governança universitária à luz da teoria da Economia dos Custos de Transação enfatizando que a compreensão do conceito de governança universitária envolve a percepção de que, diferentemente de outras $\mathbb{E}$, a universidade analisada pelos autores se caracteriza por apresentar uma intensa concentração de autoridade e autonomia nas suas unidades básicas. Nesse cenário, as estruturas de governança das universidades não tendem à neutralidade, uma vez que, as políticas e práticas universitárias encontram-se mediadas por ações de interesses de atores internos e externos.

A representação e aplicação dos principais modelos/tipologias observados nas produções científicas analisadas, neste estudo, contribuíram no processo de compreensão dos modelos de governança universitária apresentados nos Quadros 4 e 6, destacando a importância de se definir uma abordagem teórica adequada para orientar a aplicação e análise precisa dos modelos identificados. 
Diante dos elementos apresentados é possivel identificar apontamentos de modelos que convergem para orientação de governos universitários, ainda que modelos burocráticos perpassem por todos os estudos realizados, outros modelos identificados não competem entre si, pelo contrário, se complementam estabelecendo uma coexistência positiva. Nessa perspectiva, ganha destaque o modelo político que está presente em praticamente todas as pesquisas analisadas, nos quais sobressaem modelos com ações participativas que envolvem aspectos que contribuem para a definição dos modelos democráticos de governança.

Quadro 7 - Principais conceitos utilizados na construção do modelo analítico

\begin{tabular}{|l|l|}
\hline \multicolumn{1}{|c|}{ Autores } & \multicolumn{1}{c|}{ Modelos e abordagens sobre governança } \\
\hline Parnoff (2007) & Burocrático-racional, colegial, político e anarquia organizada. \\
\hline Barros (2014) & Governança do conhecimento e ética acadêmica \\
\hline Sassaki (2016) & Burocrático-racional, colegial, político e anarquia organizada. \\
\hline Félix e Furtado (2016) & Governança Participativa \\
\hline Klein, Pizzio e Rodrigues (2017) & Economia dos Custos de Transação \\
\hline Balbachevsky (2018) & $\begin{array}{l}\text { Governança da ciência - Modelo humboltiano, instrumental, democrático e } \\
\text { Empreendedor. }\end{array}$ \\
\hline
\end{tabular}

Fonte: os autores.

Nessa linha de análise, dada a contribuição por meio de periódicos científicos, os autores conceituaram de maneira tímida e indireta a governança universitária, contudo, considerando a amplitude de suas publicações, é possivel fazer algumas inferências. Para Félix e Furtado (2016), o tema é colocado como grande desafio no âmbito das políticas públicas a partir da relação entre avaliação interna e a intensidade de participação da comunidade universitária, considerando assim, como os demais autores, a qualidade da participação dos stakeholders no processo de autoavaliação institucional. Félix e Furtado (2016) afirmam também que a governança numa performance bem conduzida, pode contribuir para minimizar os entraves e problemas e agir em favor da construção de uma cultura permanente de avaliação na universidade. Balbachevsky (2017) investiga a interação entre as mudanças experimentadas na governança universitária, as alterações recentes no modo de produção do conhecimento e os novos modelos de governança da ciência, afirmando que esse processo de interação, alinhados à governança da ciência precisam se desenvolver dentro de linhas disciplinares como condição para controle da qualidade exercido por comunidades de pares fortemente conectadas, evidenciando também a importância da participação dos stakeholders nas estruturas de representação do poder para tomada de decisões. Finalmente, Klein, Pizzio e Rodrigues (2018) abordam como as universidades são realmente organizadas e governadas na prática, como funcionam e como mudam alinhadas às suas estruturas de representação do poder para tomada de decisões caracterizadas por apresentarem intensa 
concentração de autoridade e autonomia nas suas unidades básicas. Klein, Pizzio e Rodrigues (2018) evidenciam também a importância da participação dos stakeholders na estrutura de incentivos determinada pela instituição, refletindo sobre o desenvolvimento da ciência e sua estreita funcionalidade com o sistema econômico. "Desse modo, seu processo de crescimento ocorre de modo semelhante ao processo de crescimento do próprio mercado, já que é demonstrado por meio de métricas de produtividade." (KLEIN; PIZZI0; RODRIGUES, 2018, p. 5).

\section{RANKINGS E INTERFACES COM A GOUERNANÇA UNIUERSITÁRIA}

Considerando o corpus analítico evidenciado no Quadro 2, composto basicamente sobre teses acadêmicas produzidas no Brasil sobre rankings acadêmicos na educação superior brasileira (VIEIRA, 2014; BEUREN, 2014; LOURENÇO, 2014; FRANÇA, 2015; AXEL-BERG, 2015; SANTOS, 2015; RIGHETTI, 2016; SILVA, 2016; THENG0, 2018), é possivel estabelecer uma inter-relação da governança com os rankings acadêmicos, pois em todas as situações apresentadas pelos autores há ações focadas a um determinado problema ou decisão externa (regulação) que interferem nos processos de tomada de decisão (governança) das $\mathbb{E}$ ES impactando seus stakeholders.

Beuren (2014) afirma que é importante as universidades, por meio da avaliação institucional, buscarem seu autoconhecimento a fim de melhorarem sua qualidade, se inserirem regional e mundialmente, além de um bom planejamento que traga melhorias significativas à gestão de uma IES, potencializando as contribuições dessas organizações para a sociedade. Ainda, segundo Beuren (2014), na última década, os rankings surgiram como alternativa para a comparação entre as $\mathbb{E}$, aumentando sua relevância ao ponto de ser considerado no Plano de Desenvolvimento Institucional (PDI) de instituições como a Universidade Federal do Rio Grande do Sul (UFRGS) que tem como objetivo ser líder em ensino, pesquisa e extensão no Brasil e na América do Sul. Beuren (2014) apontou também que, um organizado processo de gestão considera uma aproximação com os rankings acadêmicos para que instituições como UFRGS possam se inserir de forma gradativa no cenário mundial, uma vez que a única maneira de uma universidade tornar-se de excelência é mirar além de suas fronteiras, fazendo com que o processo de internacionalização seja essencial e tratado como uma política institucional evidenciando a interface entre governança e os rankings acadêmicos.

É de interesse da UFRGS monitorar a sua posição em rankings internacionais, com o objetivo de construir uma reputação de universidade de classe mundial e manter o seu nível de excelência 
acadêmica. Para isto, se torna necessária uma análise mais profunda dos indicadores utilizados nestes rankings, a fim de se obter um maior autoconhecimento e determinar ações gerenciais. (BEUREN, 2014, p. 55).

França (2015), ao analisar os rankings universitários promovidos por jornais no espaço ibero-americano, afirmou que os rankings, apesar de terem metodologias distintas entre si, consideram relevantes aspectos relacionados à governança universitária, pois "coloca-se na agenda das universidades a necessidade de boas formas de gestão, de modo a se prestar contas à sociedade, de modo transparente, sobre de que maneira os recursos tem sido investidos, e quais são os resultados que se tem alcançado." (FRANÇA, 2015, p. 57).

Lourenço (2014) aborda a avaliação de cursos promovida pelo "Guia do Estudante", afirmando que nessa avaliação surtem efeitos em termos de gestão acadêmica, uma vez que, envolve o fascínio que os rankings despertam na comunidade educacional, tendo sua utilização em termos de gestão universitária pautada na avaliação por resultados. Os resultados da pesquisa de Lourenço (2014) revelaram uma parcela das estratégias de gestão e marketing que as IES passaram a adotar diante de ranqueamentos nacionais.

Nas produções acadêmicas de Vieira (2014), Axel-Berg (2015) e Silva (2016) são evidenciados o termo governança e sua interface com os rankings acadêmicos. Para AxelBerg (2016), os rankings são um fenômeno fundamentalmente público, possuem a capacidade de exercer poder e formar opiniões, já as universidades, por sua natureza, exigem um tipo de governança diferente de outros órgãos. As universidades não são fábricas de informações ou de força de trabalho e não devem ser medidas como tal. Axel-Berg (2015) afirma também que os rankings não são indicadores transparentes e objetivos de excelência que medem com precisão as mudanças nas instituições ano após ano, são reflexo das estruturas de poder e, em alguns casos, são produtos de interesses comerciais, em outros, um reflexo de metas específicas de desenvolvimento do estado, entretanto, lançam alguma luz sobre o desempenho das instituições e criam um poderoso discurso público para o qual as universidades são cada vez mais responsabilizadas. 0 autor defende que:

\footnotetext{
[...] em vez de fechar o caminho em que medir a pesquisa com métricas e rankings, devemos abri-la com indicadores representativos e projetos de benchmarking. Isso tornará a governança mais capaz de ser reflexiva em relação ao seu lugar na sociedade e no ensino superior global, além de trazer maior compreensão e potencial para o aprendizado compartilhado com outras instituições. Esses novos dados serão muito mais complexos do que os rankings e mais dificeis de entender como resultado, mas a comunidade acadêmica deve decidir se é preferivel avaliar as universidades com base no que é fácil de medir ou no que é genuinamente valioso. (AXELBERG, 2016, p. 127).
} 
Silva (2016) abordou a questão da governança universitária a partir da realidade da Universidade Federal de Pernambuco (UFPE) e seu desempenho em rankings entre 2013 a 2015, período em que essa universidade se destacou em diversos índices (rankings) em nível nacional e internacional. Para Silva (2016), além da demanda da sociedade por mais transparência e a imagem de confiança que a IES passa e o cuidado com a coisa pública, a governança é importante porque está intimamente ligada às grandes questões de governo democrático e "se apresenta como ferramenta de expansão e aperfeiçoamento dos meios de relação e de gestão dos conflitos de interesses, implementando políticas para aprofundar as interconexões entre governança, prestação de contas, responsividade, mediante a estrutura institucional apropriada." (SILVA, 2016, p. 19).

Em uma perspectiva semelhante à de Beuren (2014), Silva (2016) avalia a introdução das práticas de governança presentes na UFPE e sua associação com a classificação em rankings universitários. Silva (2016, p. 97) defendeu "adaptar o modelo utilizado para avaliar a presença das práticas de governança de forma a gerar um ranking (interno) e, de tal forma, ser possível verificar, quantitativamente, a relação entre governança e desempenho." 0 incremento dessas práticas de governança, segundo a autora, poderia levar a melhoria de sua avaliação nos rankings.

Vieira (2014) destaca o papel estratégico no uso dos instrumentos de avaliação comparativa, trazendo à luz da discussão, a influência dos rankings acadêmicos globais sobre esses processos, podendo observar por meio da análise das narrativas que há uma relação forte dos rankings na gestão acadêmica, discorrendo sobre os sistemas de governança das universidades, afirmando que eles ocorrem em um campo marcado por três vértices: Estado, corporações acadêmicas (ou comunidade acadêmica) e mercado. De modo mais explícito, Vieira (2014, p. 10) defende que "em um ambiente em que resida a competição, métodos avaliatório comparativos [...] são utilizados como ferramentas de gestão acadêmica na adoção de estratégias para intensificar a legitimidade dos programas stricto sensu e das universidades na esfera internacional."

Righetti (2016) se debruça na literatura científica disponivel sobre o impacto dos rankings universitários nacionais e globais na gestão das universidades e na tomada de decisão pelos alunos. Partindo desse pressuposto, a autora afirma que as universidades já não podem mais ignorar as listagens. Isso significa que as instituições de ensino cada vez mais estão alterando sua própria gestão para atender aos critérios dos rankings universitários para ganharem mais pontos nas avaliações e, consequentemente atrairem mais alunos, pais e recursos. 
De acordo com sistematização de extratos encontrados sobre o impacto dos rankings na gestão das universidades na obra de Righetti (2016), cabe destacar os discursos de reitores que declararam desejar melhorarem seus posicionamentos em diferentes rankings, além de utilizarem dos resultados das listagens para fins de marketing, e enxergar evidente esforço na contratação de docentes com premiação, ou estrangeiros por diferentes instituições, bem como, de promover prêmios com bônus em dinheiro para docentes que tiverem produção científica de impacto. Ao encontro desses achados, a autora, afirma também que "uma universidade que não integrar os critérios dos rankings na sua gestão terá uma grande chance de ser ranqueada como uma universidade de segunda classe." (VINCKE, 2009, p. 23; HAZELKORN, 2007 apud RIGUETTI, 2016, p. 141).

Santos (2015), ao analisar a influência da produção científica e o desempenho das universidades brasileiras nos rankings internacionais, a partir da organização dos elementos presentes na literatura internacional que contribuem para a definição de "universidades de classe mundial", destaca que elas devem "possuir estruturas autônomas de governança bem definidas, com liberdade para decidir sobre: temas, prioridades, currículo, processos de contratação de professores, admissão de alunos e critérios para a concessão de títulos acadêmicos e de diplomas." (SANTOS, 2015, p. 52). São características que favorecem e incentivam visão estratégica, inovação e flexibilidade para a tomada de decisões sobre a gestão dos recursos (SANTOS, 2015; THIENG0, 2018). Assim como Silva (2016) e Santos (2015), evidenciando seu impacto na governança universitária, afirma que:

\footnotetext{
Apesar das críticas à validade metodológica de determinados indicadores ou dos pesos atribuidos a eles, os rankings se tornaram um (conveniente e oportuno) instrumento de política e uma ferramenta de gestão [...], pois para sobreviver, as instituições de ensino superior estão usando os rankings para subsidiar planejamento estratégico, estabelecer objetivos e definir prioridades. (SANTOS, 2015, p. 21-22).
}

Numa linha aproximada de Santos (2015), Thiengo (2018), em sua tese de doutorado, analisa as "universidades de classe mundial" e o consenso pela excelência, apontando tendências globais e locais, ao passo em que estabelece uma interface da governança com os rankings quando afirma que os mesmos, "compõem determinado projeto de transformação ou modernização das universidades." (THIENGO, 2018, p. 123). Para a autora é preciso considerar a governança, como uma estratégia de produção de consenso que se situa numa arena de disputas. Neste enfoque, em uma perspectiva crítica a autora destaca:

Se considerarmos que, para ser bem-sucedida, a governança demanda esforços de coordenação de serviços para criar a ilusão da participação democrática, como formas inovadoras na participação política, exercícios 
de consulta, fóruns de discussão, estudos, relatórios de comparação, materiais explicativos, entre outros [...], os rankings podem ser considerados instrumentos importantes para as práticas de governança nas redes de politicas globais, tanto no que está relacionado à sua atividade "avaliativa" quanto na promoção da própria lógica da globalização. (THENGO, 2018, p. 152).

Thiengo (2018) destaca também, que rankings são tecnologias que operam via governança baseada em benchmarking, ${ }^{8}$ com os quais se cria um espaço de visibilidade internacional, acirrando-se a competitividade entre universidades, afirmação que se aproxima da produção de Axel-Berg (2016), onde a reflexão também se centra no processo de benchmarking, apontando que o mesmo tornará a governança mais capaz de ser reflexiva em relação ao seu lugar na sociedade e no ensino superior global, além de trazer maior compreensão e potencial para o aprendizado compartilhado com outras instituições. Segundo Thiengo (2018, p. 172), funciona, também como "estratégias para a produção de um consenso acerca da excelência acadêmica e científica a partir da governança por números e por benchmarking, influenciadas pelos dados dos rankings internacionais."

\section{A POLISSEMIA DO TERMO GOUERNANÇA UNIUERSITÁRIA}

0 estado da questão realizado em torno dos estudos sobre governança universitária revela que se trata de um fenômeno recente que remete, automaticamente, para um conceito altamente polissêmico. Quando se busca transpor os múltiplos significados; modelos e abordagens apontados pelos autores, encontra-se uma enorme dificuldade de conceituá-la, visto que os autores fazem distintas referências do que seria a governança universitária. Considerando a multiplicidade de objetivos dos estudos ora analisados, entre artigos científicos e teses acadêmicas, o Quadro 8 apresenta as principais obras referenciadas na literatura analisada para a fundamentação de seus respectivos conceitos apresentados sobre governança universitária, revelando a pluralidade de abordagens, não sendo assim possivel, considerar uma definição única de governança que seja compartilhada por todos os autores referenciados.

8 Processo baseado em parâmetros pré-determinados para escollha de unidade de referência para efeito de comparação e aprendizagem. Nos estudos comparativos de governança universitária, os parâmetros pré-determinados incluem: tamanho da instituição, natureza jurídica (privada ou pública), forma de financiamento, abrangência relativa às áreas de conhecimento, missão relativa à pesquisa, ensino e/ou serviços à comunidade, localização e idioma de ensino (MARCOVITCH, 2018). 
Quadro 8 - Principais obras referenciadas pela literatura cientúfica brasileira sobre a temática governança universitária

\begin{tabular}{|c|c|}
\hline AUTORES & CONCEITO DE GOVERNANÇA UNIVERSITARIA \\
\hline $\begin{array}{l}\text { Kezar e Eckel } \\
\text { (2004) }\end{array}$ & $\begin{array}{l}\text { Processo de criação de políticas e decisões de alto nível em instituições de nível superior } \\
\text { que almejam converter objetivos institucionais e recursos em resultados }\end{array}$ \\
\hline $\begin{array}{l}\text { Percy-Smith } \\
2001\end{array}$ & $\begin{array}{l}\text { Questões ligadas aos mecanismos adotados para resolver problemas coletivos, levando em } \\
\text { conta exigências e necessidades distintas e, por vezes, contraditórias entre diversos atores } \\
\text { que a compõe }\end{array}$ \\
\hline Eric (2001) & $\begin{array}{l}\text { Processos de tomada de decisão pelos quais uma instituição determina suas políticas e } \\
\text { objetivos, bem como o processo de atingi-los e monitorá-los (fortemente influenciada por } \\
\text { políticas públicas). }\end{array}$ \\
\hline Shattock (2006) & $\begin{array}{l}\text { Mecanismos e processos a partir dos quais uma universidade administra seus interesses. } \\
\text { Governança e a gestão, embora teoricamente tenham funções separadas, são inter- } \\
\text { relacionadas, no contexto universitário. }\end{array}$ \\
\hline $\begin{array}{l}\text { Kwickers (2005) } \\
\text { e Shattock } \\
\text { (2006) }\end{array}$ & $\begin{array}{l}\text { Parte da estrutura legal da instituição, abrangendo aspectos administrativos, econômicos e } \\
\text { jurídicos relacionados à forma como é estruturada e administrada internamente; como desenvolve } \\
\text { suas estratégias e políticas e as transformam em ação; como é legalmente inserida em seu } \\
\text { ambiente e/ou sistema operacional; e como a coopera com os agentes externos. }\end{array}$ \\
\hline $\begin{array}{l}\text { Olsen e } \\
\text { Maassen (2007) }\end{array}$ & $\begin{array}{l}\text { Governança frequentemente associadas a mudanças nos arranjos internos, fortalecendo } \\
\text { a liderança central e a administração, além de ser uma solução que prescreve um novo } \\
\text { paradigma organizacional, reequilibrando as relações externas e internas de autoridade e } \\
\text { poder na governança da universidade. }\end{array}$ \\
\hline $\begin{array}{l}\text { Hardy e Fachin } \\
(2000)\end{array}$ & $\begin{array}{l}\text { Estruturas de representação do poder por meio de uma clássica hierarquia burocrática, } \\
\text { caracterizada pela centralização de poder. A atividade de gestão e controle se dá numa } \\
\text { arena política, porém respeitando as decisões colegiadas. }\end{array}$ \\
\hline
\end{tabular}

Fonte: os autores.

Apesar da complexidade de se estabelecer um conceito único sobre governança universitária, fato acentuado pela polissemia do termo, analisando as obras referenciadas pelos autores (Quadro 8), percebe-se que a governança universitária está, gradativamente, inserindo-se no debate acadêmico, uma vez que tem seu foco no processo de criação de políticas e de tomada de decisões nas IES que priorizam alcançar seus objetivos institucionais (KEZAR; ECKEL, 2004). A governança, também se relaciona aos mecanismos de resolução de problemas coletivos, levando em conta exigências e necessidades distintas e, por vezes, contraditórias entre diversos atores que a compõem, por exemplo, equipe técnica e administrativa, corpo docente, corpo discente e sociedade (PERCY-SMITH, 2001). Para Eric (2001), a governança em universidades públicas sofre influência das políticas públicas que enfatizam a eficiência, já, para Kwickers (2005) e Shattock (2006), os mecanismos e processos que as universidades administram definem sua governança. Da mesma forma que, para Hardy e Fachin (2000) e Olsen e Maassen (2007), a Governança se associa às mudanças internas, fortalecendo e visando o equilibrio entre as relações externas e internas de poder na universidade. 
Apesar do alcance limitado de definições a respeito da "governança universitária", em meio às diferentes abordagens apresentadas, algumas inferências podem ser feitas a elementos mais recorrentes que fizeram jus a uma atenção especial dos autores dos estudos analisados, que vão desde apontamentos para uma escassa percepção conceitual, passando pela representação de modelos até a valorização de publicações em periódicos científicos de alto impacto como determinante de um modelo de governança do conhecimento.

Verifica-se, portanto, que apesar de objetivos tão distintos, os estudos analisados possuem focos em situações problemas relativamente pontuais (Quadro 9). No entanto, a amplitude da governança universitária vai além, podendo ser um processo altamente eficaz, principalmente, quando se constata a importância da interação política entre os atores envolvidos de forma democrática e a importância de atribuir papeis de responsabilidade na atenção aos aspectos burocráticos existentes e necessários das funções de regulação, supervisão e avaliação exercida pelo estado para que cada $\mathbb{E}$, dentro de suas particularidades, se organizem.

Quadro 9 - Objetivos de cada um dos estudos que compõem a literatura científica brasileira analisada sobre governança universitária e rankings acadêmicos

\begin{tabular}{|c|c|}
\hline Autores & Objetivos dos estudos analisados \\
\hline Parnoff (2007) & $\begin{array}{l}\text { Compreender o processo de tomada de decisão na Universidade a partir da percepção } \\
\text { dos diferentes agentes envolvidos nas decisões, procurando descrever as formas como } \\
\text { as decisões são tomadas, o envolvimento e comprometimento dos tomadores de decisões } \\
\text { e as influências políticas e administrativas neste processo. }\end{array}$ \\
\hline Barros (2014) & $\begin{array}{l}\text { Investigar a base factual por trás dos comportamentos atuais dos principais atores da } \\
\text { produção científica (docentes e pesquisadores, agências avaliadoras e de fomento, edito- } \\
\text { res e editoras de periódicos científicos) e traçar cenários para enfrentar a mudança do } \\
\text { ambiente em que a produtividade acadêmica está sendo promovida e avaliada. }\end{array}$ \\
\hline Sassaki (2016) & $\begin{array}{l}\text { Identificar as causas do desequilibrio financeiro da Universidade de São Paulo, no período } \\
\text { de } 2010 \text { a } 2014 \text {. Além disso, esta pesquisa se propõe a extrair as lições necessárias para } \\
\text { que estes desequilibrios sejam evitados no futuro. }\end{array}$ \\
\hline $\begin{array}{l}\text { Félix e Furtado } \\
\text { (2016) }\end{array}$ & $\begin{array}{l}\text { Apresentar uma discussão recorrente no âmbito das políticas públicas: a relação entre } \\
\text { avaliação interna: autoavaliação no contexto do Sistema Nacional de Avaliação da Educação } \\
\text { Superior (Sinaes) e a intensidade de participação da comunidade universitária. }\end{array}$ \\
\hline $\begin{array}{l}\text { Klein, Pizzio e } \\
\text { Rodrigues (2017) }\end{array}$ & $\begin{array}{l}\text { Lançar um olhar sobre a governança universitária à luz da teoria da Economia dos Custos } \\
\text { de Transação (ECT). }\end{array}$ \\
\hline $\begin{array}{l}\text { Balbachevsky } \\
\text { (2018) }\end{array}$ & $\begin{array}{l}\text { Investigar a interação entre as mudanças experimentadas na governança universitária, } \\
\text { as alterações recentes no modo de produção do conhecimento, e os novos modelos de } \\
\text { governança da ciência. }\end{array}$ \\
\hline
\end{tabular}

Fonte: os autores. 
Em relação a governança do conhecimento, Balbachevsky (2018) e Barros (2014) apontam para a crescente pressão para publicar em revistas de alto impacto. 0 fato gerador dessa pressão sobre as IES vem de inúmeras fontes (Estado/Agências Avaliadoras, Editoras de Periódicos Qualis, pesquisas de opinião, os próprios rankings, entre outros), ou seja, agentes de controle, regulação e/ou de cobrança por eficiência (SANTOS, 2015; AXEL-BERG, 2015; RIGHETTI, 2016). Essas forças externas contribuem para a emergência de novas lógicas institucionais no seu interior, onde docentes, discentes e funcionários precisam ser geridos e medidos, justificando os mecanismos da governança do conhecimento.

Na abordagem dos autores (PARNOFF, 2007; FÉLIX; FURTADO, 2016; SASSAKI, 2016; SILVA, 2016; KLEIN; PIZZI0; RODRIGUES, 2018), identificou-se que a governança universitária é tratada como uma possibilidade de desenvolver uma atuação mais responsável. Também, vista como mecanismo de acompanhamento do rendimento dos alunos dos cursos de graduação em relação aos conteúdos, assim como, a implantação de prêmio de excelência acadêmica institucional, prêmio condicionado à disponibilidade orçamentária. Ainda, de acordo com os autores, a governança universitária é uma ação participativa em espaços de conflitos e jogos de interesse e poder, espaço onde se acompanha a análise dos impactos sobre os processos decisórios e os recursos financeiros dentro de uma matriz institucional, que permitem que as transações sejam negociadas e executadas a partir de mecanismos que buscam reduzir os custos ou, ainda, a maneira como uma IES se organiza para oferecer seu serviço.

Figura 2 - Aspectos conceituais de governança identificados nas obras pesquisadas

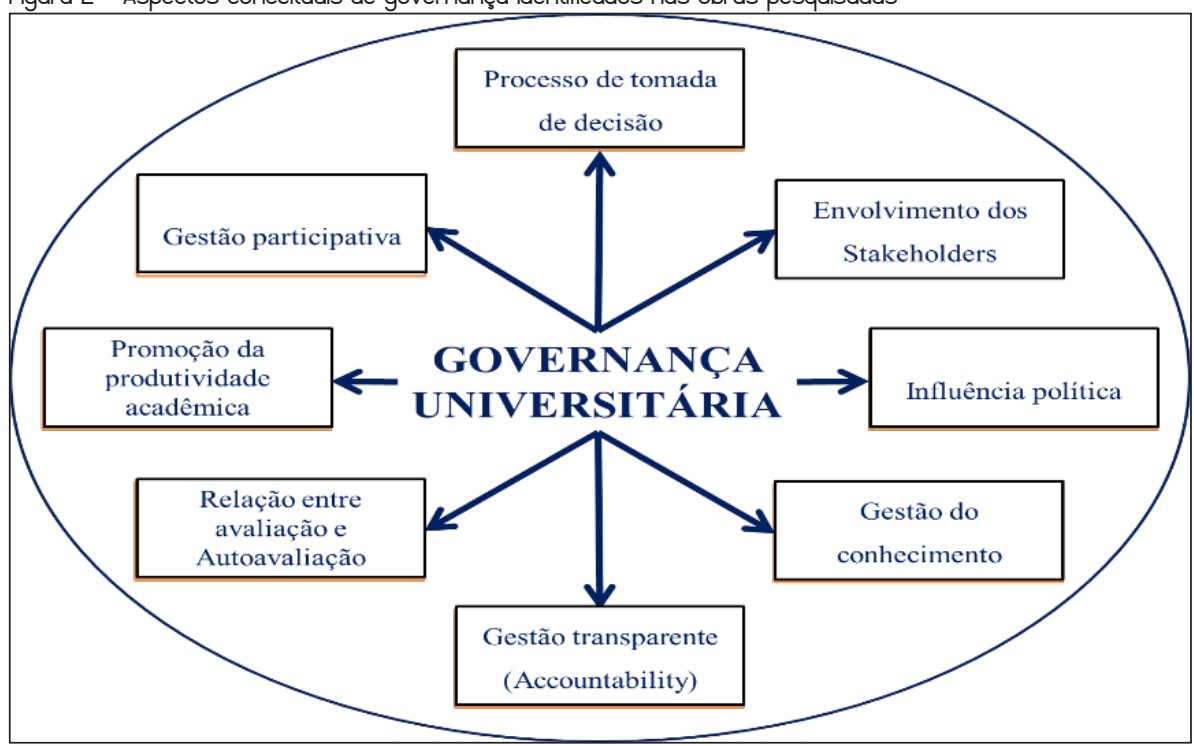

Fonte: os autores. 
Considerando os aspectos conceituais abordados (PARNOFF, 2007; FÉLIX; FURTADO, 2016; SASSAKI, 2016; KLEIN; PIZZIO; RODRIGUES, 2018) e diante das particularidades presentes e analisadas, a Figura 2 apresenta os principais aspectos conceituais de governança que, de certa forma, compreende um conjunto de elementos que remetem há uma forte inter-relação com os rankings acadêmicos, pois verificou-se a presença de interesses na consolidação de uma cultura avaliativa nas IES, assim como atenção dada a avaliação do desempenho dos estudantes, concessão de prêmios, atrelada ao desempenho em Rankings, performance nas classificações internacionais de universidades, reconhecimento e valorização das ações de seus docentes e servidores, bem como, o envolvimento de seus stakeholders. Nessa interrelação, verificou-se também o aperfeiçoamento das políticas de accountability, bem como, métricas de produtividade e indicadores de produção científica, ampliação das capacidades de conduzir uma gestão transparente, visando colocar a universidade numa posição estratégica e de destaque frente ao mercado.

\section{CONCLUSÕES}

Para a conclusão deste artigo elaborou-se um quadro analitico representado na Figura 3. Um aspecto identificado é a multiplicidade de modelos teóricos, fato que caracteriza a polissemia do termo governança universitária na literatura acadêmica brasileira, não sendo possível identificar convergências para um conceito único de governança. Destacandose na análise a presença dos modelos teóricos: 1) burocrático-racional, colegial, político e anarquia organizada (PARNOF, 2007; SASSAKl, 2016); 2) modelo de governança participativa (FELIX; FURTADO, 2016); 3) governança financeira a partir do modelo de Economia dos Custos de Transação (KLEIN; PIZZIO; RODRIGUES, 2017); 4) modelos teóricos humboltiano, instrumental, democrático e Empreendedor (BARROS, 2014; KLEIN; PIZZIO; RODRIGUES, 2017; BALBACHEVSKY, 2018) e; 5) governança do conhecimento e ética acadêmica (BARROS, 2014; BALBACHEVSKY, 2018). 
Figura 3 - Governança universitária e sua inter-relação com os rankings acadêmicos

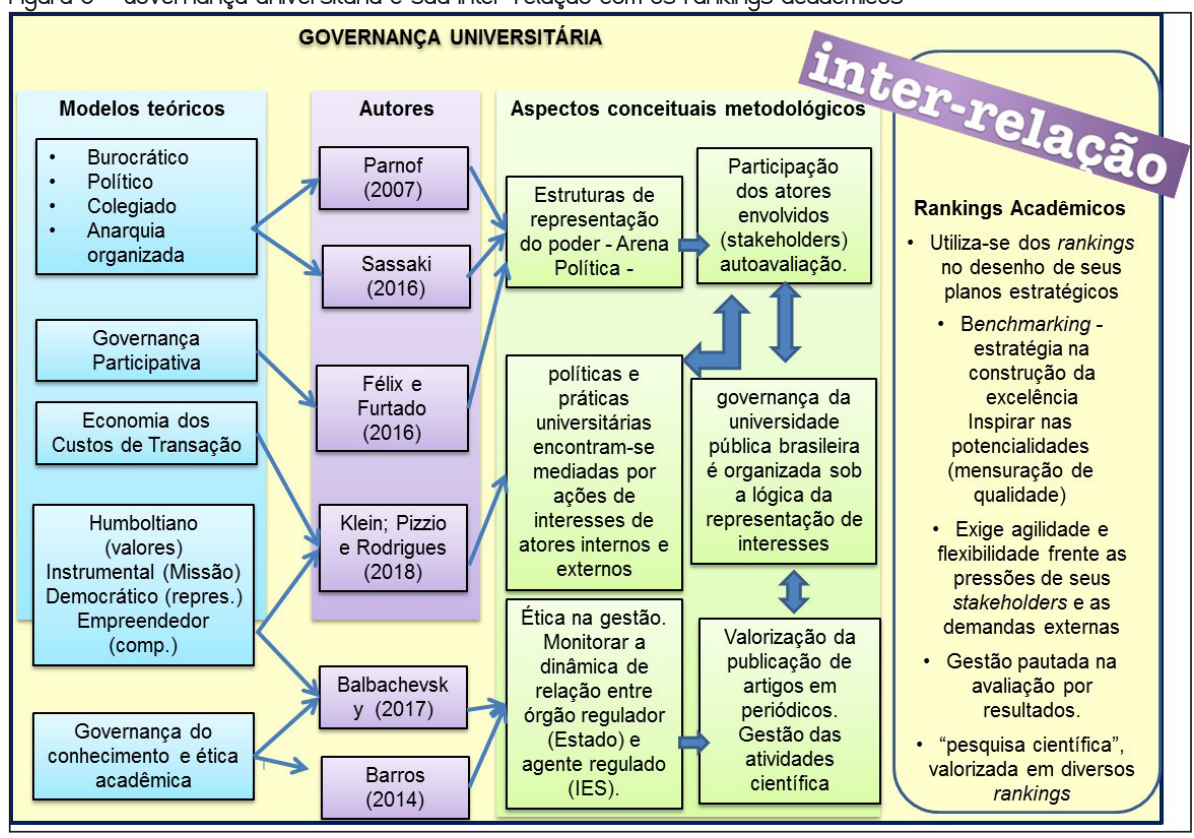

Fonte: os autores.

Observando a Figura 3, quando se remete aos aspectos conceituais, identificouse que alguns passam a se convergirem, como (p.e) a criação de políticas e processos de tomada de decisões nas universidades que almejam converter objetivos institucionais em resultados, assim como, uma universidade administra seus interesses de forma transparente; outro aspecto identificado são os mecanismos adotados para solução de problemas coletivos e de como a governança universitária é frequentemente associada às mudanças nos arranjos internos, além de ser identificada como uma solução que prescreve um novo paradigma organizacional, reequilibrando as pressões e demandas externas e internas de autoridade e poder.

Ainda, na Figura 3, pode se observar a inter-relação identificada da governança universitária com os rankings acadêmicos, sendo estes, ferramentas importantes de governança, quando são considerados pelas universidades, 1) quando da elaboração de seus planos estratégicos; 2) no uso de benchmarking como estratégia de gestão, a partir dos dados e resultados gerados pelos próprios rankings levando as universidades inspirarem nas potencialidades de outras instituições ou evitarem as fragilidades identificadas (VIEIRA, 2014; BEUREN, 2014; AXEL-BERG, 2016; THIENGO, 2018) e; 3) na disponibilidade de informações geradas potencializando as boas práticas, facilitando a comparação entre as universidades (SANTOS, 2015). 
Diante do conjunto de produções acadêmicas analisadas e aos aspectos reunidos e organizados na Figura 3, pode-se afirmar que o conceito de governança universitária está alinhado a uma estrutura ágil e flexível no processo de tomada de decisão, frente a um cenário de grandes mudanças e múltiplas demandas, ultrapassando aos conceitos básicos de gestão, este entendimento alinha-se ao conceito de governança universitária de Brunner (2011) que a define como sendo a capacidade que a universidade tem de se pensar a longo prazo e de se adaptar ao cenário de mudanças, por meio de ações internas efetivas, para tomada de decisões estratégicas, de maneira que assegure sua continuidade.

\section{REFERÊNCIAS}

AXEL-BERG, J. H. Competing on the world stage: the Universidade de São Paulo and global universities rankings. 2015. Dissertação (Mestrado em Relações Internacionais) - Universidade de São Paulo, 2015.

BALBACHEVSKY, E. Governança na pesquisa científica: reflexões sobre a prática da pesquisa contemporânea e a experiência brasileira. Sociologias, v. 19, n. 46, p. 76-101, 2017. D0l: http://dx.doi. org/10.1590/15174522-019004603.

BARROS, M. 0 modelo brasileiro de governança acadêmica e seus efeitos na produtividade científica. 2014. Tese (Doutorado em História das Ciências e das Técnicas e Epistemologia) - Universidade Federal do Rio de Janeiro, Rio de Janeiro, 2014.

BEUREN, G. M. Avaliação da qualidade institucional através de rankings nacionais e internacionais. 2014. Dissertação (Mestrado em Engenharia de Produção) - Universidade Federal do Rio Grande do Sul, Porto Alegre, 2014.

BRUNNER, J. J. Gobernanza universitaria: tipología, dinámicas y tendencias. Revista de Educación, v. 355, p. 137-159, 2011.

BRUNNER, J. J.; GANGA CONTRERAS, F. Reflexiones en torno a economía política y gobernanza de los sistemas nacionales e instituciones de educación superior en América Latina. Interciencia, v. 41, n. 8, p. 573-579, 2016.

CALDERÓN, A. I. 0 Brasil segue na contramão dos rankings acadêmicos. Folha de São Paulo, 18 ago. 2017. Disponível em: http://ruf.folha.uol.com.br/noticias/2017/09/1918941-rankings-academicos-o-brasil-na-contramao.shtml. Acesso em: 18 ago. 2018.

CALDERÓN, A. I.; WANDERCIL, M.; MARTINS, E. (org.). Rankings acadêmicos e governança universitária no espaço do ensino superior de língua portuguesa: Angola, Cabo Verde, Macau, Moçambique, Portugal e Brasil. Brasilia, DF: Anpae, 2019.

CAPES. Catálogo de Teses e Dissertações. [S. l.]: Capes, 2018a. Disponivel em: https://catalogodeteses. capes.gov.br/catalogo-teses/\#!/. Acesso em: 5 dez. 2019. 
CAPES. Portal de Periódicos. [S. l]: Capes, 2018b. Disponivel em: https://www.periodicos.capes.gov.br/. Acesso em: 5 dez. 2019.

CHIAVENATO, I. Introdução a Teoria Geral da Administração. [S. l.: Makron Books, 1998.

CNPq. Plataforma Lattes. Disponível em: http://lattes.cnpq.br/. Acesso em: 12 dez. 2019.

ERIC, A. Higher Education Report. ASHE Higher Education Report, v. 28, n. 1, 2001. Disponível em: http:// onlinelibrary.wiley.com/journal/10.1002/(ISSN)1536-0709/issues?activeYear=2001. Acesso em: 25 maio 2018.

FANELLI, A. G.; CARRANZA, M. P. Los rankings y sus usos en la gobernanza universitária. Revista lberoamericana de Ciencia, Tecnología y Sociedad - CTS, v. 13, n. 37, p. 95-112. 2018.

FÉLIX, G. T.; FURTADO, D. B. V. Autoavaliação Institucional e (In)Cultura de Participação na Universidade. HOLOS, v. 1, p. 69-80, 2016. D0l: https://doi.org/10.15628/holos.2016.2151.

FRANÇA, C. M. Rankings universitários promovidos por jornais no espaço ibero-americano: El Mundo (Espanha), El Mercurio (Chile) e Folha de São Paulo (Brasil). 2015. Dissertação (Mestrado em Educação) - Pontificia Universidade Católica de Campinas, Campinas, 2015.

HARDY, C.; FACHIN, R. C. Gestão estratégica na universidade brasileira: teoria e casos. 2. ed. Porto Alegre: Ed. Universidade/UFRGS, 2000.

KEZAR, A.; ECKEL, P. D. Meeting today's governance challenges. Journal of Higher Education, v. 75, n. 4, p. 371-399, 2004. D01: https://doi.org/10.1080/00221546.2004.11772264

KLEIN, K.; PIZZIO, A.; RODRIGUES, W. Governança universitária e custos de transação nas universidades da Amazônia legal brasileira. Educação \& Sociedade, v. 39, n. 143, 2018. D0l: http://dx.doi.org/10.1590/ es0101-73302018176926.

KWICKERS, P. Governing governance: organization law and network - process - design. International Journal for Education Law and Policy, v. 1, p. 73-102, 2002.

LOURENÇO, H. F. Os rankings do Guia do Estudante na educação superior brasileira: um estudo sobre as estratégias de divulgação adotadas pelas instituições que obtiveram o prêmio melhores universidades. 2014. Dissertação (Mestrado em Educação) - Pontifícia Universidade Católica de Campinas, Campinas, 2014.

MARCOVITCH, J. Repensar a Universidade: desempenho acadêmico e comparações internacionais. São Paulo: Com-Arte; Fapesp, 2018.

MERTON, R. K.; DEUS, J. D. A crítica da ciência: sociologia e ideologia da ciência. 2. ed. Rio de Janeiro, RJ: Zahar, 1979. 
OLSEN, J. P.; MAASSEN, P. European debates on the knowledge institution: the modernization of the university at the European level. In: MAASSEN, P.; OLSEN, J. P. University dynamics and European integration. Dordrecht: Springer, 2007. p. 3-22.

OROZCO, L. A.; CHAVARRO, D. A. Robert K. Merton (1910-2003): la ciencia como institución. Revista de Estudios Sociales, n. 37, p. 143-162, dez. 2010.

PARNOFF, L. 0 processo decisório em uma burocracia profissional - implicações políticas e racionalidade administrativa - o caso da UNIJUÍ. 2007. Dissertação (Mestrado em Desenvolvimento) - Universidade Regional do Noroeste do Estado do Rio Grande do Sul, ljuí, 2007.

PERCY-SMTH, J. Local governance in Britain. Basingstoke: Palgrave, 2001.

REDE RANKINTACS. Rede Brasileira de Pesquisa em Rankings, Índices e Tabelas Classificatórias na Educação Superior. Acervo Digital. Disponivel em: https://rederankintacs.wixsite.com/acervo. Acesso em: 12 dez. 2018.

RIGHETTI, S. Qual é a melhor? Origem, indicadores, limitações e impactos dos rankings universitários. 2016. Tese (Doutorado em Política Científica e Tecnológica) - Universidade Estadual de Campinas, Campinas, 2016.

SANTOS, A. V. et al. Governance: concepts and emergence in Brazilian education. Ensaio: Avaliação e Políticas Públicas em Educação, v. 24, n. 93, p. 939-967, 2016. D0l: http://dx.doi.org/10.1590/S010440362016000400008.

SANTOS, S. M. 0 desempenho das universidades brasileiras nos rankings internacionais: áreas de destaque da produção científica brasileira. 2015. Tese (Doutorado em Ciência da Informação) - Universidade de São Paulo, São Paulo, 2015.

SARTORI, R. Governança em agentes de fomento dos sistemas regionais de CT\&l. 2011. Tese (Doutorado em Engenharia e Gestão do Conhecimento) - Universidade Federal de Santa Catarina, Florianópolis, 2011.

SASSAKI, A. H. Governança e conformidade na gestão universitária. 2016. Tese (Doutorado em Economia, Administração e Contabilidade) - Universidade de São Paulo, São Paulo, 2016.

SHATTOCK, M. Managing good governance in higher education. Berkshire, England: Open University, 2006.

SILVA, M. C. C. A governança nas instituições de ensino superior: o caso da Universidade Federal de Pernambuco. 2016. Dissertação (Mestrado em Administração) - Universidade Federal de Pernambuco, Recife, 2016.

THERRIEN, J.; NÓBREGA-THERRIEN, S. Os trabalhos científicos e o estado da questão: 
reflexões teórico-metodológicas. Estudos em avaliação educacional, v. 15, n. 30, 2004.

THENGO, L. C. Universidades de classe mundial e o consenso pela excelência: tendências e manifestações globais e locais. 2018. Tese (Doutorado em Educação) - Universidade Federal de Santa Catarina, Florianópolis, 2018.

UNIVERSIDADE DE SÃO PAUL0. Resolução n. 5483, de 6 de novembro de 2008. Instituiu o Prêmio Excelência Acadêmica Institucional USP. Diário Oficial do Estado, 8 nov. 2008. Disponivel em: http://www.usp. br/imprensa/wp-content/uploads/Portaria_premio.pdf. Acesso em: 15 maio 2019.

VIEIRA, R. C. A internacionalização da pós-graduação no Brasil: a relação entre os rankings acadêmicos globais e avaliação dos programas de pós-graduação em Administração. 2014. Dissertação (Mestrado em Administração) - Escola Superior de Propaganda e Marketing, São Paulo, 2014.

WANDERCLL, M.; CALDERÓN, A. I.; GANGA-CONTRERAS, F. Qualidade da educação superior no Brasil: desempenho das universidades católicas à luz dos rankings acadêmicos, índices e tabelas classificatórias estatais e do setor privado. EccoS - Revista Cientifica, n. 51, p. e14581, 2019. D0l: https://doi. org/10.5585/eccos.n51.14581.

WANDERCLL, M.; CALDERÓN, A. I. Governança e desempenho das universidades católicas à luz do Ranking Universitário Folha (RUF). Série-Estudos, v. 25, n. 54, p. 89-116, maio/ago. 2020. D0l: http:// dx.doi.org/10.20435/serie-estudos.v25i54.1335.

Endereço para correspondência: Rua Professor Dr. Euryclides de Jesus Zerbini, 1516, Parque Rural Fazenda Santa Cândida, 13087-571, Campinas, São Paulo, Brasil; adolfo.ignacio@puc-campinas.edu.br 